\title{
Relatos de transição capilar sob o olhar de uma crespa
}

Reports of a hair transition under the eyes of a curly girl

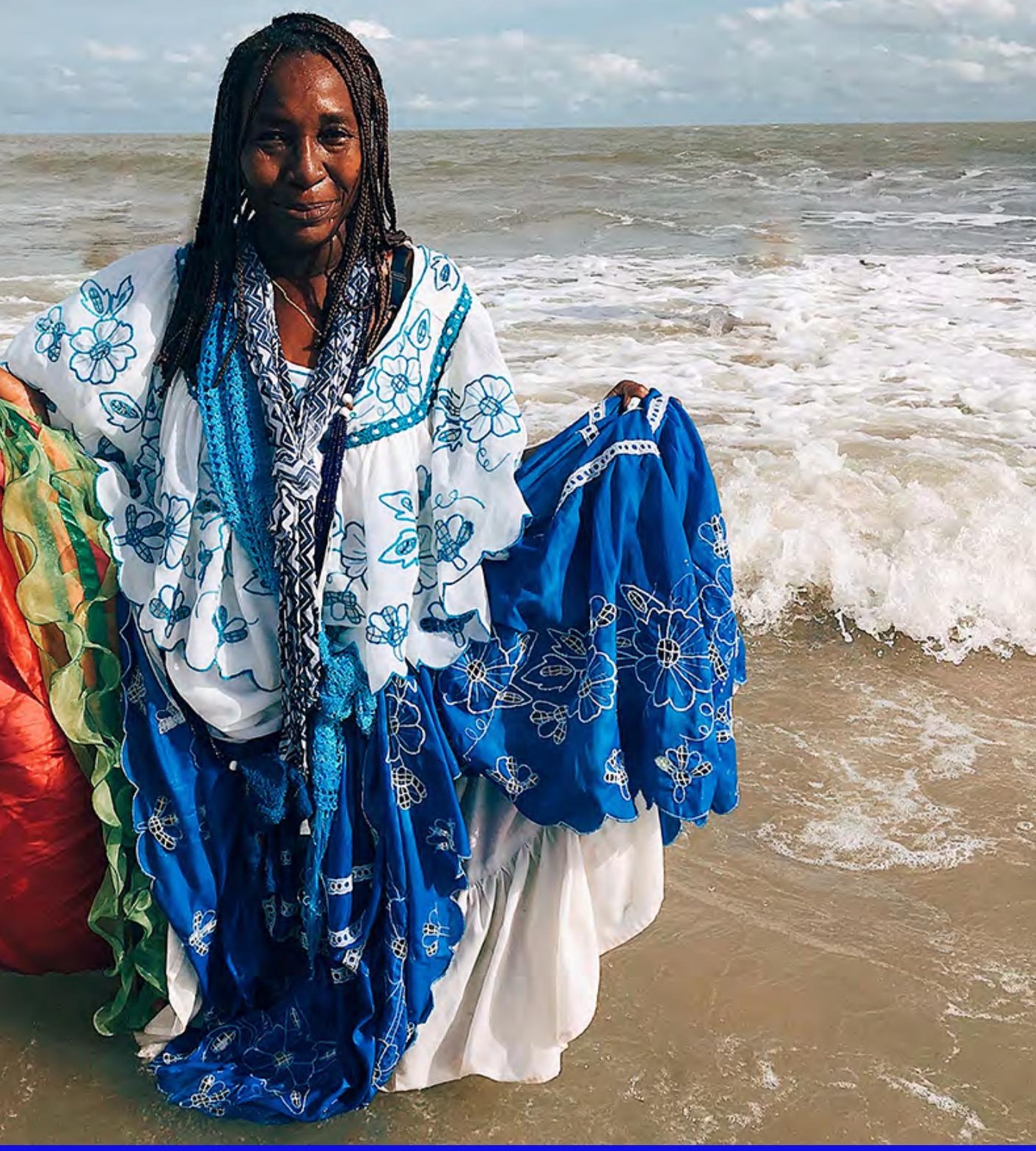




\section{Kátia Xavier-Zeca1}

ORCID: https://orcid.org/0000-0003-1381-2991

[resumo] Nos últimos tempos, tem se vivenciado, movimentos de identidade associados à representatividade e à aceitação do cabelo natural. Assumir os fios como eles são tem sido uma forma de empoderamento e grito de liberdade ante a opressão vivida sob os modelos estéticos eurocêntricos. Seja no Brasil, seja na África, a exaltação pela aceitação do cabelo natural ganha força. Esse é o contexto do artigo Relatos de transição capilar sob o olhar de uma crespa, cujo objetivo é abordar processos vivenciados por algumas mulheres de Moçambique que passaram a exibir o seu cabelo natural. 0 foco está nas suas experiências e vivências. Para este artigo, recorreu-se à revisão documental embasada nos preceitos teóricos de bell hooks ${ }^{2}$, complementada com a técnica de amostragem por conveniência. Os dados foram reunidos por meio de um questionário aplicado a moçambicanas que fazem uso das redes sociais (Facebook). Levando em conta os resultados da pesquisa, pode-se concluir que a maioria das entrevistadas considera o processo de transição bom, sente-se satisfeita com a escolha e concorda que os produtos para cabelo natural são caros. Vale ressaltar que muitas dessas mulheres têm optado por tratar o cabelo em casa.

\section{[palavras-chave] Cabelo Natural. Carapinha. Identidade. Transição capilar.}

[abstract] In recent times, identity movements associated with the representativeness and acceptance of natural hair have been experienced. Taking on the threads as they are has been a form of empowerment and a cry for freedom in the face of oppression experienced under Eurocentric aesthetic models. Whether in Brazil or in Africa, an exaltation for the acceptance of natural hair gains strength. This is the context of the article Capillary transition reports under the eyes of a curly, whose purpose is to address processes experienced by some women in Mozambique who change to show their natural hair. The focus is on your experiences. For this article, a document review based on bell hooks theoretical precepts was used, complemented by the convenience sampling technique. The data were gathered through an application applied to Mozambicans who use social networks (Facebook). Taking into account the results of the research, it can be said that most of the interviewees consider the transition process to be good, feel satisfied with the choice and agree that the products for natural hair are expensive. It is worth mentioning that many of these women have chosen to treat their hair at home.

[keywords] Natural hair. Carapinha. Identity. Capillary transition.

Recebido em: 16-01-2020

Aprovado em: 07-09-2020

\footnotetext{
${ }^{1}$ Doutoranda em Ciência Política na UFRGS. Mestre em Desenvolvimento e Cooperação Internacional pelo Instituto Superior de Economia e Gestão da Universidade Técnica de Lisboa. Professora assistente na Universidade Joaquim Chissano, Moçambique. E-mail: Ksarahxavier@gmail.com. Lattes: http://lattes. cnpq.br/5335246354929729.

2 bell hooks é o pseudônimo de Gloria Jean Watkins, norte-americana nascida em 25 de setembro de 1952 , Hopkinsville, Kentucky, EUA. Acadêmica e ativista que vem trabalhando com as questões de raça, gênero e classe. bell hooks assumiu seu pseudônimo, o nome de sua bisavó, para homenagear os legados femininos. Ela preferia soletrá-lo com todas as letras minúsculas para chamar a atenção para sua mensagem e não para si mesma. Disponível em: https://www.britannica.com/biography/bell-hooks. Acesso em 7. nov. 2020.
} 


\section{Introdução}

A aparência e a preocupação com o visual têm sido motivo de inquietação feminina ao longo dos séculos. Passa-se anos sem saber como é de fato o cabelo original de muitas mulheres. São décadas de negação e fuga do natural, e várias justificativas podem ser dadas para essa questão. Porém, o que me instigou a realizar este estudo é o que as moçambicanas pensam sobre o assunto e como têm vivenciado o processo de transição capilar. Da infância à vida adulta, como se mostra o relacionamento com o Eu natural? O que mudou? Como mudou? No contexto moçambicano, as mulheres que optam pelos fios originais são chamadas de carapinhas ${ }^{3}$ ou tema natural. Nesse sentido, importa falar, refletir e indagar. Hoje em dia, vive-se um momento em que produtos, ou mesmo salões de beleza, estão disponíveis para o tratamento e os cuidados do cabelo natural. Graças a um forte movimento de aceitação do próprio cabelo, muitas mulheres decidiram dar adeus aos alisamentos e aposentar a chapinha para exibirem seus cachos.

Nesse emaranhado de ideias, surge a necessidade de escrever os relatos de transição capilar sob o olhar de uma carapinha, ou seja, de alguém que passou pelo mesmo processo, mas sem que a sua experiência faça parte dos depoimentos aqui apresentados.

O intuito do artigo é contribuir para o debate sobre a transição capilar em Moçambique, discussão essa que, no Brasil, tem tomado dimensões inimagináveis em torno da afirmação da identidade e do empoderamento feminino. Esse movimento, inclusive, levou a indústria cosmética a repensar e a rever as suas estratégias e a investir em linhas destinadas ao crespo natural.

Interessa ainda questionar e refletir a respeito da relação entre cabelo e transição capilar. Para isso, foram essenciais as leituras de trabalhos que relacionam a questão dos crespos ao racismo, como hooks (1989) e Kilomba (2019), ou mesmo que incidem sobre os processos de retorno à textura original dos fios, casos de Oliveira (2019) e Silva (2016).

Desde 2014, tem se verificado em Moçambique uma proliferação de grupos nas redes sociais, bem como de salões de cabeleireiro, dedicados à comercialização e à troca de experiências sobre produtos para cabelos naturais. Entre eles, destaco o grupo do Facebook Carapinhas do Índico, a marca Bradas da Nossa Carapinha, o Xi3 Cabeleireiro \& Spa e o salão Afrocêntrico.

Em termos metodológicos, o artigo procedeu da revisão documental em torno das temáticas cabelo e transição capilar complementada com a aplicação de um questionário às mulheres que fazem uso do Facebook. A técnica para seleção dos casos foi por meio de amostragem por conveniência e resultou em 20 respondentes que relataram sobre como é assumir o cabelo natural e ser carapinha em Moçambique. Os resultados foram tratados de forma qualitativa e quantitativa com o recurso do Pacote Estatístico para as Ciências Sociais (SPSS $)^{4}$, o qual permitiu fazer análise descritiva dos dados colhidos.

\footnotetext{
${ }^{3}$ Carapinha é a designação para o cabelo muito crespo e denso, comum em pessoas negras. Disponível em: https://dicionario.priberam.org/carapinha. Acesso em: $16 \mathrm{dez}$. 2019. Termo muito usado no contexto moçambicano para designar o cabelo normalmente natural, livre de químicas, e de difícil trato.

${ }^{4}$ Do inglês Statistical Package for the Social Sciences.
} 


\title{
Cabelo natural e a sua aceitação
}

Hooks (1989) relata, na sua obra Talking back: thinking feminist, thinking black, a relação que as negras americanas tinham com o cabelo e explica os processos de alisamento com pente aquecido, um ritual pelo qual muitas passaram. Ter fios lisos poderia ser vantajoso no momento de procurar emprego e no acesso a outros benefícios laborais.

Falar de cabelo vai além de abordá-lo apenas como adorno estético, pois ele pode ter vários significados e impactar diferentemente a vida de cada ser humano em dimensões inimagináveis. Segundo Vieira,

\footnotetext{
“Cabelo, cabeleira, cabeludo, descabelado.... Considerado por muitos apenas um instrumento estético, o cabelo vai muito além disso. Uma simples opção por um corte ou penteado diz bastante sobre a personalidade de uma pessoa. Para os negros, especialmente, que desde a década de 1950 desfilam com seus black power imponentes, ele transcende o campo da beleza e significa um encontro com a identidade e, porque não, uma ferramenta de afirmação. (VIEIRA, 2019, p. 1)
}

O enunciado acima revela que a corrente pela afirmação negra não é atual. De tempos em tempos, ela ressurge e ganha mais força, incorporando outras dimensões de luta. Já nas décadas de 1950 e 1960, ações em prol da beleza e da valorização do natural foram realçadas pelo movimento black power, nos Estados Unidos da América, e o que hoje assistimos é uma continuidade e uma ressignificação desses ideais.

Os anos 1960 representam um momento importante para o uso do cabelo como instrumento de revolta política:

\begin{abstract}
Durante a década de 1960, os negros que trabalharam ativamente para criticar, desafiar e mudar o racismo branco apontaram para a maneira pela qual a obsessão dos negros por cabelos lisos refletia uma mentalidade colonizada. Foi nessa época que o penteado natural, o "afro", tornou-se moda como sinal de resistência cultural à opressão racista e como celebração da negritude. Os naturais foram equiparados à militância política. (HOOKS, 1989, p. 2)
\end{abstract}

A adoção do cabelo natural tem sido uma luta de longos anos, pois os fios crespos estão associados a algo ruim, criando desde cedo uma aversão a esse tipo de textura capilar. Essa negação e esse preconceito têm acompanhado a infância ou mesmo a juventude de muitas mulheres. Oliveira (2016) chama atenção para vários apelidos pejorativos que normalmente são associados às madeixas crespas:

\footnotetext{
Tradução minha para: "During the 1960s black people who actively worked to critique, challenge, and change white racism pointed to the way in which black people's obsession with straight hair reflected a colonized mentality. It was at this time that the natural hairdo, the "afro," became fashionable as a sign of cultural resistance to racist oppression and as a celebration of blackness. Naturals were equated with political militancy".
} 
Há anos o cabelo crespo é mal visto na nossa sociedade. Muitas vezes é chamado de "cabelo ruim", outras de "cabelo mal cuidado", até mesmo "cabelo sem jeito". Aquele famoso cabelo que precisa ser controlado. Qual a menina de cabelos crespos após se arrumar, e estar pronta para sair de casa, nunca ouviu a seguinte pergunta: "Não vai pentear o cabelo, não? Vai sair com ele bagunçado? Passa uma mão molhada para abaixar". Frases como essas são ditas todos os dias, além dos muitos apelidos que os cabelos crespos possuem. (OLIVEIRA, 2016, p. 220)

A evolução histórica mostra que várias batalhas foram travadas pelas mulheres pelo direito de vestirem aquilo que mais lhes trazia conforto - e o valor delas é muitas vezes associado à aparência (HOOKS, 2000). Ter a possibilidade de andar com os fios ao natural, sem seguir o padrão eurocêntrico, é outra das lutas femininas ao longo dos séculos (VIEIRA, 2019). Essa reivindicação não se resume apenas às questões físicas, mas também à apresentação do cabelo. Tem se assistido uma tentativa de as mulheres mostrarem o quão são belas mesmo assumindo os seus fios naturais, já que, segundo Vieira (2019), elas têm sido condicionadas, desde o tempo da escravidão, a alisarem o cabelo. A reflexão sobre o belo também é levantada por Kilomba (2019) ao apontar que a negritude está associada a algo que não é bom ou belo, mas sim repugnante.

Constantemente, as discussões e os questionamentos a respeito do cabelo ocorrem em vários espaços, seja o acadêmico, seja o local de trabalho, e em certa medida conectam-se ao debate sobre o racismo. Essas questões relacionam-se ao fato de a pessoa ser aceita ou não pela sociedade por causa da aparência do seu cabelo natural (OLIVEIRA, 2016, 2019). Durante muito tempo, mulheres negras submetem-se a processos de mudança de visual que as aproximam da aparência das brancas, já que a sociedade cria mecanismos em que ter cabelo liso torna a pessoa mais aceitável ou até mesmo supostamente organizada. Por meio da indústria cosmética, essas ideias se enraizaram, principalmente pela abundante oferta de produtos químicos que permitem o alisamento e tornam o cabelo como o das brancas, que é considerado o ideal e o mais bonito. Ter o crespo natural é, então, visto como algo feio e que deve sempre ser penteado (EUGÉNIO JR., 2018).

As questões em torno do cabelo e do racismo têm sido debatidas simultaneamente, pois, em muitos momentos, as pessoas sofrem discriminação por terem os fios crespos e por não seguirem as características eurocêntricas ${ }^{6}$ e aceitáveis pela sociedade (cabelo liso) (EUGÉNIO JR., 2018; KILOMBA, 2019; PAULA, 2014).

$\mathrm{O}$ alisamento como estratégia de adestramento social é muito bem retratado por Oliveira, ao referir que:

\footnotetext{
0 eurocentrismo é uma visão de mundo baseada em valores europeus, colonizadores ou racistas. Assim, esse conceito descreve o processo em que a Europa se constitui como o centro de poder no mundo, principalmente com a colonização. Contudo, mesmo após o fim do período colonial, muitos aspectos sociais continuam eurocêntricos. Disponível em: https://www.todoestudo.com.br/sociologia/eurocentrismo. Acesso em: 8 set. 2020. Importa realçar que o cabelo liso não é exclusivo da mulher europeia. As asiáticas, assim como as indígenas, têm esse mesmo tipo de fio.
} 
O alisamento dos cabelos como uma forma de adestramento é validado com a manifestação de aprovação de pessoas do círculo de convivência, das redes de relacionamentos, e é expresso por meio de elogios e sugestões de manutenção definitiva do alisamento. Nas situações em que esse alisamento não ocorre, ele aparece como uma exigência para se adequar ao ambiente, como, por exemplo, para ser admitida no trabalho. A repulsa ao cabelo crespo é tão intensa que atinge até gerações futuras com a indicação de que mulheres de cabelos crespos deveriam buscar parceiros de cabelos lisos para "salvar" seus filhos de terem cabelos crespos. (OLIVEIRA, 2019, p. 55)

Esse processo de negação e recusa acompanhou as mulheres negras durante séculos. E mesmo com a massificação da aceitação dos cabelos crespos, reside ainda o preconceito contra aquelas que assumem o seu cabelo natural.

Em 2015, o Jornal Domingo 7 publicou um artigo no qual abordava o retorno da beleza dos crespos. Uma de suas argumentações era a de que se vivia, em Moçambique, uma maior valorização da cultura e da mulher africanas, associada à estética e aos cabelos. Nesse sentido, tem se assistido em todo o mundo, e Moçambique não ficou alheio, a um movimento de mulheres que incentiva a retomada da identidade africana. Com a escravatura e a colonização, os africanos e seus descendentes foram alvos de mutilação cultural, adotando padrões impostos pela civilização europeia. 0 cabelo crespo das negras alimentou, em grande medida, o preconceito racial e era visto como desprovido de beleza. Algumas mulheres passaram mesmo pela obrigação de cortá-lo. Na tentativa de assimilar a cultura ocidental, adotaram processos penosos de alisamento com pente quente e química para tornar seus fios lisos como os das mulheres brancas, deixando-os mais parecidos com os do colono (JORGE, 2015).

No seu artigo, Jorge (2015) ressalta como as questões culturais em torno do cabelo crespo estão enraizadas na história da humanidade:

As imposições culturais esboçaram espécie de revolução mundo fora. É impossível falar da história do cabelo crespo sem fazer referência à obra intitulada 400 Years Without a Comb [400 anos sem um pente, em português], obra de Willie L. Morrow. 0 livro ressalta a humilhação de escravos africanos na América devido ao cabelo crespo. A obra mostra como o negro viveu na sociedade americana, abordando, por exemplo, a invenção do pente, mencionando a descoberta de processos químicos de preparação de cremes desfrisantes para tornar o cabelo da mulher negra mais liso. Estes produtos tiveram muita repercussão de tal forma que até hoje a América tem se destacado na sua produção. (JORGE, 2015, p. 1)

\footnotetext{
7 Jornal veiculado em Moçambique aos domingos. Publicação em 3 de outubro de 2015. Disponível em: https:// uww.jornaldomingo.co.mz/index.php/sociedade/7521-o-retorno-a-beleza-do-crespo. Acesso em: 10 dez. 2019.
} 
Kilomba (2019) apresenta uma excelente definição sobre o ser diferente, na qual ele é nomeado dessa maneira porque não tem as características às quais a sociedade está habituada. A autora também aborda na sua obra, Memórias da Plantação: episódios de racismo cotidiano, alguns questionamentos que muitas crespas sofrem ao longo da sua existência: "Como você lava seu cabelo?", “Ou querem saber se eu o penteio: Você penteia seu cabelo?" (KILOMBA, 2019, p. 123). A pesquisadora ainda ressalta que essas perguntas nunca são feitas no sentido inverso, de uma negra para uma branca, se esta lava ou penteia o cabelo, mas a mulher negra constantemente é bombardeada com estas questões.

As redes sociais exercem um papel primordial na disseminação e na aceitação do cabelo natural em Moçambique, apesar de o país não oferecer internet de forma expandida tanto para o celular quanto para o computador (INSTITUTO NACIONAL DE ESTATISTICA, 2019) ${ }^{8}$. Porém, os que têm acesso são influenciados e obtêm informação nessas redes, que vão desde o Facebook até o Instagram. Por meio de diferentes plataformas de comunicação, é possível despertar nas pessoas o orgulho e a valorização da carapinha, partilhar experiências e ensinar como cuidar dos fios crespos. Enfim, são espaços que incentivam a adoção do cabelo natural crespo (JORGE, 2015).

Em Moçambique, a sociedade ainda não encara o cabelo natural como sendo algo dotado de beleza. Existe muito preconceito, e o cabelo crespo e os dreadlocks são conotados à marginalidade ou à falta de cuidado. Outras vezes, os dreads são vistos como sinal de rebeldia ou dos contrários ao sistema (JORGE, 2015). Apesar das várias resistências e da rejeição em torno do cabelo crespo ou natural, essa tendência tem ganhado cada vez mais seguidoras que redescobriram formas de autoafirmação e de identidade. Mesmo que no local de trabalho sejam vistas como rebeldes ou despenteadas, as mulheres não se retraem e continuam a luta para conquistar seu espaço.

\section{0 processo de transição capilar}

De acordo com Ferrari e Assis, "a transição capilar é abordada enquanto um fenômeno social caracterizado pelo abandono dos tratamentos químicos que modificam as características naturais dos cabelos por grupos de indivíduos" (FERRARI; ASSIS, 2017, p. 74). Importa referir que esse fenômeno social não é novo e, com a evolução do capitalismo, outras formas de fazer face ao politicamente correto em termos de aparência capilar têm sido colocadas no mercado. A transição capilar é uma fase de mudanças. Embora tudo comece com o desejo de assumir os fios naturais, a transição é capaz de mudar mais do que isso (T0DECACHO, 2019) ${ }^{9}$. É um momento de conquista e aceitação do Eu como mulher crespa que

\footnotetext{
8 Moçambique tem uma população total de 27.909.798 habitantes e, de acordo com os dados do último censo, apenas $26,4 \%$ dela tem celular e $5,1 \%$ tem computador. Tanto um como outro meio podem ser instrumentos que permitem o acesso à internet. Disponível em: http://www.ine.gov.mz/iv-rgph-2017/ mocambique/apresentacao-resultados-do-censo-2017-1. Acesso em: $17 \mathrm{dez}$. 2019.

9 Disponível em: https://www.todecacho.com.br/blog_section/transicao-capilar/. Acesso em: 10 dez. 2019.
} 
exibe o próprio cabelo com as suas perfeições e imperfeições, e cria formas e mecanismos de cuidar dele sem que seja algo ruim e depreciável.

A maioria das mulheres que optou pelo processo de transição capilar em algum momento da vida passou por questionamentos sobre o seu cabelo, apelidado de duro, ruim, feio e outras palavras depreciadoras que contribuíram para uma menor aceitação dos fios originais, criando assim, desde cedo, uma necessidade de querer mudá-los para algo considerado socialmente belo e aceitável, como o liso com características eurocêntrica33s (FERRARI; ASSIS, 2017).

Em Moçambique, país que esteve sob o domínio colonial português até 1975, subsistem resquícios dessa supremacia no que tange à aceitação do cabelo natural ou crespo. Apesar de a maioria dos habitantes serem negros, muitas são as moçambicanas que, desde a infância, não têm um relacionamento saudável com seus fios originais, optando por diferentes formas de alisamento que lhes permitam uma certa semelhança com a mulher branca. Ferrari e Assis (2017) referem que mesmo no Brasil, um mosaico cultural e com parte da população de ascendência africana, persiste fortemente o preconceito, fazendo com que inúmeras pessoas submetam-se a "cirurgias plásticas, alisamentos e diversas outras técnicas a fim de se afastar cada vez mais de suas raízes étnico-raciais” (FERRARI; ASSIS, 2017, p. 75).

De acordo com a blogueira Lorena Morais, criadora do blog Encrespando, "o primeiro passo para aceitar a transição é a paciência. Afinal, esperar o cabelo crescer e eliminar toda a parte da química (que por sinal está bastante danificada) exige muito de você" (MORAIS, 2013, p. 1) ${ }^{10}$. Essa aceitação é bastante pertinente, pois, em alguns momentos, a dificuldade para tratar o cabelo natural advém do não saber esperar e da ansiedade para que os resultados da transição sejam logo visíveis.

Várias expressões têm sido empregadas para descrever os fios sem química, entre as quais, as mais comuns são: "cabelo natural", "cabelo crespo", "cabelo cacheado", "cabelo afro" (MATOS, 2016, p. 846) ou cabelo carapinha ${ }^{11}$. Cada uma dessas designações tem a sua especificidade, que pode estar vinculada à não utilização de produtos químicos (cabelo natural) ou, ainda, à aparência dos fios (crespo ou cacheado) (quadro 1). 0 importante é que, crespo, ondulado ou afro, todos esses tipos de fio englobam aquilo que designamos como cabelo natural, livre de químicas e de qualquer transformação, independentemente do aspecto adquirido após o processo de transição capilar.

\footnotetext{
10 Disponível em: https://lorenamorais.wordpress.com/2013/11/20/da-quimica-ao-natural-o-processo-de-transicao-capilar/. Acesso em: 15 nov. 2019.

11 Termo muito usado no contexto moçambicano para designar o cabelo normalmente natural (sem químicas), de difícil trato.
} 
QUADRO 1 - TIPOS DE CABELO

\begin{tabular}{|l|l|}
\hline Tipos de cabelos & $\begin{array}{l}\text { Descrição } \\
\text { Refere-se a um suposto estado de natureza, é o cabelo que } \\
\text { nasce com determinada característica e não passa por qualquer } \\
\text { processo que altere sua estrutura. Esse tipo de fio pode ser } \\
\text { tratado com diferentes produtos, industrializados ou não, e } \\
\text { ainda receber uma texturização que modifique a sua aparência } \\
\text { temporariamente, o oposto do que ocorre quando são utilizadas } \\
\text { químicas de transformação. }\end{array}$ \\
\hline Cabelo crespo e cabelo cacheado & $\begin{array}{l}\text { Termos relacionados à aparência do cabelo ondulado, espiralado } \\
\text { ou encrespado e que também denotam uma disputa na qual } \\
\text { os crespos são os mais próximos com os fios africanos. Assim, } \\
\text { aquelas que os possuem teriam mais legitimidade ao se } \\
\text { assumirem como negras, já que as cacheadas não seriam alvo } \\
\text { de tanto preconceito, uma vez que esse formato de fio está mais } \\
\text { próximo do cabelo que é considerado bom. }\end{array}$ \\
\hline Cabelo afro & $\begin{array}{l}\text { Palavra mais englobante pois reúne os vários tipos de cabelos } \\
\text { que as pessoas com herança negra, a partir da sua carga genética, } \\
\text { podem exibir. }\end{array}$ \\
\hline
\end{tabular}

FONTE: Adaptado pela autora com base em MATOS, 2016.

Para efeitos desta pesquisa, mencionarei o cabelo natural como aquele livre de química ou de qualquer outra mudança que recorra do alisamento ou da transformação por meio de outros produtos. Em algum momento, também usarei o termo carapinha, forma usual para designar o cabelo natural de mulheres negras em Moçambique.

Importa realçar como Oliveira (2019), na sua dissertação, faz menção à trajetória de negação dos cabelos crespos das mulheres negras, retratando ainda o momento de sua soltura, mostrando como elas passaram por processos de sobrevivência e chegaram aos dias atuais com o conhecimento das novas formas de lidar com o cabelo crespo.

\section{Relatos de vinte mulheres sobre a transição capilar}

Em Moçambique, tem se verificado a proliferação de grupos nas redes sociais, e até mesmo de mulheres individualmente, que colaboram para a disseminação dos cuidados e tratamentos específicos com o cabelo natural/crespo. Há que se destacar ainda os salões de beleza especializados em cabelo natural. Nesse sentido, realçamos aqui a comunidade Carapinhas do Índico, do Facebook, criada em 2014 e com 15.191 membros. 0 salão Bradas da Nossa Carapinha, que possui uma página no Facebook desde 2014 com 34.046 seguidores. Citamos ainda o Xi3 Cabeleireiro \& Spa, com página no Facebook desde 2017 e 2.532 seguidores, e, por fim, o salão Afrocêntrico, com 1.182 seguidores no Facebook, fundado em 2000. Esses são apenas alguns dos locais e marcas especializados em cabelo natural. Contudo, vale ressaltar que o Afrocêntrico é o mais antigo a enveredar pelo cuidado dos fios originais, bem como o primeiro salão em Moçambique com uma linha de produtos $100 \%$ natural e local ${ }^{12}$.

\footnotetext{
12 Carapinha existia para cuidar apenas de Cabelos Naturais e o penteado "DREADLOC" veio a ser o seu principal serviço, no qual se tornou muito rapidamente uma referência nacional e por sua vez Internacional visto que era o único salão, na altura, a oferecer exclusivamente este tipo de serviço e com muita qualidade, diga-se de passagem. Disponível em: https://carapinha.co.mz/sobre-cadino-chipanga/. Acesso em: 6 jul. 2020. Por favor, ver o texto desta nota: está confuso e não é possível acessar o site.
} 
Os relatos deste artigo resultam de narrativas de 20 mulheres que utilizam, com alguma frequência, as redes sociais Facebook e Instagram e têm em comum o fato de ostentarem o cabelo natural/crespo. Como instrumento de coleta de informações utilizou-se um questionário, disponibilizado eletronicamente entre os dias 1으 de novembro e 31 de dezembro de 2019, às usuárias do Facebook que fazem parte da comunidade Carapinhas do Índico. Os dados foram analisados recorrendo-se ao pacote estatístico para as ciências sociais (SPSS) por meio da análise descritiva do material obtido.

A faixa etária das entrevistadas está entre 30 e 45 anos de idade e todas têm curso superior completo (graduação), e, em alguns casos, pós-graduação (mestrado e doutorado). Uma parcela delas iniciou a transição capilar há menos de 12 meses, mas a maioria está nesse processo há mais de cinco anos. Parte significativa dessas mulheres refere que a experiência em ser crespa tem sido boa, apesar de apresentar desafios.

Ser crespa representa um momento de liberdade ou de afirmação de identidade, como diz a entrevistada $\mathrm{M}^{13}$ :

\begin{abstract}
Considero um "relacionamento" simples e tranquilo. Por ter um fio muito crespo, nunca me dei bem com defrisagem (não pegava) e comecei desde cedo uma relação de amor com o meu cabelo natural, embora sempre que pudesse num estilo protetor. Honestamente, não vejo os contras porque não desenvolvo rotinas complicadas e nem o trato como um bebê que precisa de uma atenção extra. Sou uma pessoa bastante irreverente e ainda que no trabalho sempre olhassem para mim como quem diz "lá vai ela com o estilo próprio" e achassem graça, para mim era apenas criação de identidade".
\end{abstract}

Apesar das dificuldades para manter e cuidar do cabelo crespo, em termos gerais, o balanço, depois de terem passado pelo processo de transição, é bastante satisfatório e pode-se considerar um caminho sem volta. Há, ainda, quem refira que passou a se ver mais bela ao assumir os seus cachos naturais. A falta de tempo e algumas complicações enfrentadas pelas inquiridas não afetam na preferência que nutrem por ter assumido a sua carapinha (quadro 2).

\footnotetext{
${ }^{13}$ Entrevistada M.Entrevista [Dez. 2010]. Maputo, 2019. Áudio captado por via de chamada telefônica. Resposta obtida por meio de questionario online.
} 


\section{QUADRO 2 - DESAFIOS, PRÓS E CONTRAS NOS CUIDADOS}

COM O CABELO CRESPO/NATURAL

- Bom e complicado.

- Exige tempo e paciência

- Tem sido uma maravilha.

- Nunca gostei de cabeleireiro e a ideia de não ter que estar várias horas num salão,-associado ao facto de não precisar pentear, tem sido fantástica.

- Relacionamento bom, apesar de ter que lutar com pente, apenas fico com preguiça quando se trata de mudar de penteado.

- Muito bom, só que infelizmente tenho bastante medo de pentear.

- Cuidar do cabelo natural é difícil, mas o relacionamento com o meu cabelo é muito bom.

- Cuidar do cabelo da forma correta.

- Muito bom e me sentindo muito leve.

- Hoje em dia, está mais tranquilo porque eu aprendi a cuidar dele, mas antes eu não tinha paciência e não gostava de como ele ficava.

- Como tinha um padrão de beleza na minha cabeça, eu me comparava e me achava feia.

- Positivo, tenho dreads há 17 anos e sou feliz com eles. Só vejo vantagens, cabelo longo a baixo custo, liberdade para usá-lo como quiser. Cobiça, admiração e respeito pela sociedade em geral.

- No princípio, foi complicado, mas durante esses quase cinco anos aprendi a conhecer o meu cabelo e hoje ele se comporta conforme

o meu desejo. É um processo de aprendizagem e paciência.

- Tem sido muito bom, muitos desafios superados.0 F

- Tudo normal e não passei por uma transição, pois sempre usei cabelo natural.

- Bom. Entretanto, tenho dificuldades em mantê-lo hidratado. Ainda estou a descobrir que produtos se adequam melhor a ele.

- Bom, o cabelo obedece facilmente aos penteados com qualquer tipo de gel ou creme.

- Resseca com facilidade e encolhe muito, mas é fácil de cuidar.

- Difícil mantê-los em bom estado por muito tempo.

- Desafio é manter a carapinha com vida.

- Poucos salões que saibam tratar o cabelo natural.

- Sofrer críticas por não diversificar o penteado.

- Tem sido um relacionamento muito bom, vou descobrindo novas formas para hidratar e tratar o cabelo.

FONTE: Dados da pesquisa feita pela autora, 2019.

Quando questionadas sobre os constrangimentos que passaram após assumirem o cabelo natural, mais de $60 \%$ das entrevistadas referem que enfrentaram algum tipo de aborrecimento, enquanto $40 \%$ revelam nada ter sofrido (tabela 1). E entre as que encararam tais constrangimentos, a maior parte delas, $40 \%$, sentiu-os no local de trabalho; $15 \%$ entre amigos; e ainda $10 \%$ no salão de cabeleireiro (tabela 2).

\section{TABELA 1 - CONSTRANGIMENTO APÓS ASSUMIR O CABELO NATURAL}

\begin{tabular}{ccc}
\hline & Respostas das entrevistas & Porcentagem \\
Não & 8 & $40 \%$ \\
Sim & 12 & $60 \%$ \\
Total & 20 & $100 \%$ \\
\hline
\end{tabular}

FONTE: Elaborada pela autora.

TABELA 2 - SITUAÇÕES EM QUE PASSOU CONSTRANGIMENTO

\begin{tabular}{ccc}
\hline & Respostas das entrevistas & Porcentagem \\
Nenhuma & 6 & $30 \%$ \\
Local de trabalho & 8 & $40 \%$ \\
Amigos & 3 & $15 \%$ \\
Salão de cabeleireiro & 2 & $10 \%$ \\
Outras situações & 1 & $5 \%$ \\
Total & $\mathbf{2 0}$ & $\mathbf{1 0 0 \%}$ \\
\hline
\end{tabular}

FONTE: Elaborada pela autora. 
Mesmo as lutas e os movimentos pelo cabelo natural não sendo novos, algumas das nossas entrevistadas relataram vários episódios quando questionadas por quais constrangimentos tinham passado no processo de transição capilar. Situações que ocorreram no convívio com amigos, no local de trabalho ou, ainda, no salão de cabeleireiro (quadro 3).

\section{QUADRO 3 - RELATOS DE CONSTRANGIMENTOS VIVENCIADOS POR MULHERES CRESPAS}

\footnotetext{
- As pessoas pegam muito para ver se é real.

- Na verdade, acho que só já me vi numa situação dessas uma vez em que alguém me perguntou se a ideia era andar como estou. 0 resto tem sido apenas elogios.

- Esqueci-me de pentear os meus colegas tiveram que me emprestar um xaile para servir de lenço.

- Chamaram de despenteada.

- Uma colega que dizia que não posso ocupar um cargo de direção com minha carapinha.

- Minhas amigas me perguntarem o porquê de eu ter cortado o cabelo e fazerem uma cara de insatisfação. De viajar para a Argentina

e as pessoas quererem tocar no meu cabelo.

- No salão, as cabeleireiras não sabem tratar cabelo natural.

- Sou uma pessoa bastante irreverente e ainda que no trabalho sempre olhassem para mim como quem diz "lá vai ela com o estilo próprio" e achassem graça, para mim era apenas criação de identidade.

- Algumas pessoas tendem a questionar a minha opção.

- Alguém se ofereceu para me emprestar uma prótese capilar ${ }^{14}$, pois alegava que deveria ir diferente ao corte do bolo de meu aniversário. Já estavam cansadas de me verem ao natural.

- Alguns comentários: gostava mais do cabelo como estava...
}

FONTE: Dados da pesquisa feita pela autora, 2019.

Do total das inquiridas, a maior parte delas, 45\%, iniciou o processo de transição capilar por vontade própria, enquanto $25 \%$ sofreram influência de amigos ou colegas, $15 \%$ de familiares, $10 \%$ do companheiro (a); e 1\% recebeu outras influências (tabela 3).

\footnotetext{
${ }^{14}$ Essa é uma pergunta complicada, porque não existe uma definição "oficial" dos termos que permita diferenciá-los com $100 \%$ de autoridade. Nos Estados Unidos, aparentemente o termo "prótese capilar" surgiu para permitir que pacientes que tivessem a perda de cabelo como consequência de uma doença, acidente ou tratamento pudessem classificar os gastos com essas peças como despesas médicas, e conseguir que eles fossem cobertos pelos planos de saúde e deduzidos do imposto de renda. Algumas pessoas defendem que a peça só é uma prótese se for utilizada nesse contexto médico. Outras postulam que a diferença é que a peruca fica presa na cabeça apenas com elásticos, presilhas ou grampos, enquanto a prótese é aderida à cabeça do usuário com adesivos ou cola específica, o que permite que a pessoa pratique esportes, tome banho ou entre na piscina sem precisar retirá-la. Uma terceira opinião é a de que a prótese pode ser feita para cobrir áreas menores da cabeça, de acordo com a necessidade do cliente, enquanto a peruca é sempre uma peça que cobre a cabeça inteira. DIsponivel em: https://www.chegadequeda.com.br/tudo-que-voce-precisa-saber-sobre-protese-capilar. Acesso em 10 nov 2020. Em Moçambique existem vários tipos de adorno capilar. A prótese capilar assemelha-se a uma peruca. Porém o processo de aplicação é diferente.
} 
TABELA 3 - INFLUÊNCIAS NO PROCESSO DE TRANSIÇÃO

\begin{tabular}{lcc}
\hline & Respostas das entrevistas & Porcentagem \\
Nenhuma influência/vontade própria & 9 & $45 \%$ \\
Amigos/colegas & 5 & $25 \%$ \\
Familiares & 3 & $15 \%$ \\
Companheiro/a & 2 & $10 \%$ \\
Outras & 1 & $5 \%$ \\
Total & 20 & $100 \%$ \\
\hline
\end{tabular}

FONTE: Elaborado pela autora

As redes sociais que as entrevistadas mais utilizam são o Facebook e o Instagram e, consequentemente, é nesses dois veículos que procuram informação sobre como tratar ou cuidar do cabelo natural, bem como experiências ou ainda testemunhos de pessoas que estejam a passar pelos mesmos processos (tabela 4).

TABELA 4 - USO DE REDES SOCIAIS

\begin{tabular}{|c|c|c|c|c|c|c|}
\hline \multirow[b]{4}{*}{ Frequentemente } & \multicolumn{6}{|c|}{ Qual das seguintes redes sociais usa: } \\
\hline & \multicolumn{2}{|c|}{ Instagram } & Twitter & & \multicolumn{2}{|c|}{ Facebook } \\
\hline & $\begin{array}{c}\text { Respostas das } \\
\text { entrevistas }\end{array}$ & Porcentagem & $\begin{array}{c}\text { Respostas das } \\
\text { entrevistas }\end{array}$ & Porcentagem & $\begin{array}{l}\text { Respostas } \\
\text { das } \\
\text { entrevistas }\end{array}$ & Porcentagem \\
\hline & 9 & 45 & & & 10 & 50 \\
\hline Às vezes & 4 & 20 & & & 10 & 50 \\
\hline Nunca & 7 & 35 & 20 & 100 & & \\
\hline Total & 20 & 100 & 20 & 100 & 20 & 100 \\
\hline
\end{tabular}

FONTE: Elaborada pela autora.

A maior parte das crespas opta por tratar o cabelo em casa (65\%) e 35\% recorrem ao salão de cabeleireiro. Como existe pouca oferta de locais especializados em cabelo natural, esta pode ser uma das razões que levam as pessoas a cuidarem elas mesmas dos seus fios. Outro aspecto relevante é o custo dos cosméticos para cabelo natural. Muitas das entrevistadas consideram os preços caros ou extremamente caros (45\%) e 40\% não acham nem caros nem baratos, enquanto apenas 10\% julgam que os produtos não são muito caros (tabela 5). 
TABELA 5 - PREÇO DOS PRODUTOS PARA CABELO NATURAL

Não muito caros

Caros

Nem caros, nem baratos

Extremamente caros
10

40

45

5

FONTE: Elaborada pela autora.

Inúmeras são as dificuldades encontradas quando se fala nos cuidados com o cabelo natural. Algumas delas relacionadas com a falta de tempo ou com questões financeiras. E, como já referido, alguns dos produtos são considerados caros. São apresentados, ainda, problemas ligados ao cuidado com o cabelo, como falta de variedade de penteados, tratamento ou adequação dos cosméticos (quadro 4).

\section{QUADRO 4 - DIFICULDADES ENCONTRADAS PARA CUIDAR DO CABELO NATURAL/CRESPO}

\begin{tabular}{|c|c|}
\hline Indicador & Depoimentos \\
\hline Tempo & - Tempo \\
\hline $\begin{array}{l}\text { Tratamento/Pentear/Falta de variedade de } \\
\text { penteados }\end{array}$ & $\begin{array}{l}\text { - Pentear. } \\
\text { - As únicas dificuldades que tenho é em relação aos cabeleireiros não } \\
\text { oferecerem variedade de penteados para cabelo natural. Todos fazem quase } \\
\text { o mesmo. } \\
\text { - Tenho dificuldades na hidratação. }\end{array}$ \\
\hline Distância do salão de cabeleireiro & • Distância com relação ao salão onde frequento. \\
\hline Adequação dos produtos/Tratamento & $\begin{array}{l}\text { - Encontrar produto que se dê bem com o meu tipo de cabelo e ter tempo } \\
\text { suficiente para fazer o cronograma capilar. } \\
\text { - No tratamento do cabelo. } \\
\text { - É um pouco difícil encontrar os produtos que utilizo na minha cidade. }\end{array}$ \\
\hline Financeiras & - Financeira, visto que os produtos são caros. \\
\hline Nenhuma Dificuldade & - \\
\hline
\end{tabular}

FONTE: Dados da pesquisa feita pela autora, 2019. 


\section{Conclusão}

O movimento black power que ocorreu nos Estados Unidos da América (anos 1950, 1960) não foi exclusivo da região. Teve reflexos em outras sociedades, reinventando-se ao longo dos tempos e, atualmente, é percebido com bastante ênfase na questão da identidade associada ao cabelo natural.

Durante muito tempo, ter o cabelo crespo ou natural foi visto como algo ruim ou negativo, o que influenciou a vida pessoal e social principalmente das mulheres. Apresentar-se com padrões de beleza eurocêntricos (cabelos lisos) tornou-se um dos objetivos para que elas fossem consideradas bonitas, tendo em conta o cabelo que ostentavam.

A valorização da mulher frequentemente está associada à sua estética (traços finos, pele clara, fios lisos e organizados). Exibir o cabelo natural ou crespo é visto como algo desorganizado e de péssima aparência. Para evitar isso, é necessário recorrer ao alisamento, tornando-se apresentável perante a sociedade. Essa discriminação ocorre em vários espaços: familiar, escolar e local de trabalho, entre outros, nos quais homens e mulheres são vítimas de preconceito em razão da aparência natural do seu cabelo.

Nesse contexto, o processo de transição capilar tem sido para as mulheres um grito de liberdade e redescobrimento da sua beleza, permitindo que abandonem produtos químicos e outros métodos para alisar ou transformar a aparência do seu cabelo. Apesar de um momento difícil, a transição capilar é de extrema importância quando se fala acerca da aceitação dos próprios fios, pois quebra o ciclo de produtos e de alienação do eu por meio de substâncias químicas e outros mecanismos de modificação do cabelo.

Com base nos relatos colhidos, pode-se concluir que ainda existe um grande preconceito e dúvidas, por parte de terceiros, sobre o fato de determinada mulher assumir o seu cabelo natural/crespo. É notório que a maioria delas passou por um certo constrangimento e sempre existe alguém com uma inquietação em torno da sua aceitação como crespa/natural.

Mesmo em meio aos questionamentos, inclusive de outras mulheres, que incluem desde não conseguir tratar sozinha ou não ter tempo para ir ao salão de cabeleireiro até o preço elevado dos produtos para manutenção, todas se dizem bastante satisfeitas com a opção de assumir os próprios fios.

Conclui-se também que, para essas crespas, é um caminho sem volta. Denota-se pelas narrativas que ser natural as liberta, no sentido que muitas delas desenvolvem um novo modo de se relacionar com o seu cabelo, sem que ele seja visto como uma característica ruim. Cabelo natural enxergado, então, como algo lindo e que torna a mulher ainda mais bela, lutando contra toda a imposição eurocêntrica de se ter o cabelo liso ou considerado arrumado. 


\section{Referências}

ARAUJO, Marta; RODRIGUEZ MAESO, Silvia.; MENESES, Maria Paula G. Racismo e cidadania. JANUS, [s. l.], 2010, p. 116-117. Disponível em: https://www.janusonline.pt/arquivo/ popups2010/2010_3_1_8.pdf. Acesso em: 1 jun. 2020.

EUGÉNIO JR., Amauri. Por que a sua “opinião” sobre cabelos crespos é racismo? 2018. Disponível em: https://www.vice.com/pt_br/article/mb5yq8/cabelos-crespos-racismo. Acesso em: 16 dez. 2019.

FERRARI, Érica.; ASSIS, Juliana. A dimensão informacional da transição capilar: identidade e empoderamento nas mídias sociais. Revista Brasileira de Educação em Ciências da Informação, [s. l.], v. 4, n. 1, 2017, p. 74-95. Disponível em: http://abecin.org.br/ portalderevistas/index.php/recebi\%3E. Acesso em: 17 dez. 2019.

HOOKS, Bell. Straightening our hair. In: Talking back: thinking feminist, thinking black. New York: South end Press, 1989.

HOOKS, Bell. Feminism is for everybody: passionate politics. Canada: South end Press, 2000. Disponível em: doi: 10.4324/9781315743189-3. Acesso em: 12 dez. 2019.

INSTITUTO NACIONAL DE ESTATÍSTICA. Resultados definitivos: censo 2017 IV Recenseamento Geral da População e Habitação. 2019. Disponível em: http://www.ine.gov. mz/iv-rgph-2017/mocambique. Acesso em: 15 fev. 2020.

JORGE, Luísa. O Retorno a beleza do crespo. Jornal Domingo, Maputo, 2015. Disponível em: https://www.jornaldomingo.co.mz/index.php/sociedade/7521-o-retorno-a-belezado-crespo. Acesso em: 10 dez. 2019.

KILOMBA, Grada. Políticas do cabelo. In: Memórias da plantação: episódios de racismo cotidiano. Rio de Janeiro: Cobogo, 2019. p. 121-132.

MATOS, Lídia. Transição capilar como movimento estético e político. In: Seminário Nacional De Sociologia da UFS, 2016, Sergipe. Anais... Sergipe: Editora, 2016, p. 845-858.. Disponível em https://ri.ufs.br/bitstream/riufs/12871/2/TransicaoCapilarMovimento.pdf . Acesso em: 17 dez. 2019.

MORAIS, Lorena. Da química ao natural: o processo de transição capilar. 2013. Disponível em: https://lorenamorais.wordpress.com/2013/11/20/da-quimica-ao-natural-o-processode-transicao-capilar/. Acesso em: 15 nov. 2019.

OLIVEIRA, Danielle Christina do Nascimento. Meu cabelo não é só estética, é também política: os movimentos sociais e as narrativas visuais. Revista da ABPN, [s. l.], v. 8, n. 20, 2016, p. 217-230. 
OLIVEIRA, Ivani Francisco de. Versões de mulheres negras sobre a transição capilar: um estudo sobre processo de descolonização estética e subjetiva. Dissertação (Mestrado em Psicologia Social) - Pontifícia Universidade Católica de São Paulo, São Paulo, 2019. Disponível em: https://tede2.pucsp.br/bitstream/handle/22176/2/Ivani Francisco de Oliveira.pdf. Acesso em: 06 jul. 2019.

PAULA, Bruna de. 0 que cabelo tem a ver com racismo? Geledés. 2014. Disponível em: https:// www.geledes.org.br/o-que-cabelo-tem-ver-com-racismo/. Acesso em: 17 dez. 2019.

SILVA, Célia Regina Reis da. Crespos insurgentes, estética revolta memória e corporeidade negra paulistana, hoje e sempre. Tese (Doutorado em História Social) -- Pontifícia Universidade Católica de São Paulo, São Paulo, 2016. Disponível em: https://tede2.pucsp.br/ bitstream/handle/19003/2/Célia Regina Reis da Silva.pdf. Acesso em: 6 jul. 2019

VIEIRA, Kauê. Black power: instrumento de resistência e cultura. 2019. Disponível em: http://www.afreaka.com.br/notas/black-power-instrumento-de-resistencia-e-cultura/. Acesso em: 16 dez. 2019. 